\title{
Evaluating the Frequency, Co-occurrence, and Psychosocial Correlates of Childhood Multiple Victimization
}

\author{
Lyzon K. Babchishin \\ University of Ottawa \\ Elisa Romano \\ University of Ottawa
}

\begin{abstract}
The current study was designed to contribute to our growing understanding of childhood multiple victimization (i.e., exposure to more than one type of victimization), which has been found to be the reality among most victimized children. Caregivers of school-aged children $(N=213)$ completed an online and anonymous questionnaire that assessed the victimization experiences (lifetime) and psychosocial functioning of their child, as well as collecting information on a number of socio-demographic factors. Results provide support for the ubiquitous nature of childhood multiple victimization (86.9\%), as well as the common cooccurrence of lifetime victimization experiences $\left(M_{\text {exposure }}=6.58\right)$. Findings highlight the important association between victimization exposure and psychosocial functioning (e.g., anxiety, depression, aggression, posttraumatic stress). The practical and theoretical implications for the prevention of childhood victimization are also discussed.
\end{abstract}

Keywords: childhood victimization, co-occurrences, preventative programs

\section{RÉSUMÉ}

Cette étude porte sur la victimisation multiple (c.-à-d., exposition à plus d'un type de victimisation), qui est une expérience courante chez les enfants avec un historique de victimisation. Les parents d'enfants d'âge scolaire $(N=213)$ ont rempli dans l'anonymat un questionnaire sur internet, évaluant les expériences de victimisation et le fonctionnement psychologique de leurs enfants. Les résultats démontrent la présence

Lyzon K. Babchishin, School of Psychology, University of Ottawa, ON; Elisa Romano, School of Psychology, University of Ottawa, ON.

Correspondence concerning this article should be addressed to Dr. Lyzon K. Babchishin, School of Psychology, University of Ottawa, Vanier Hall, Room 4023, 136 Jean Jacques Lussier, Ottawa, ON K1N 6N5. Email: Ibabc080@uottawa.ca 
courante de la victimisation multiple $(86,9 \%)$ ainsi que la cooccurrence entre les différentes expériences de victimisation $\left(M_{\text {exposition }}=6,58\right)$. Les résultats démontrent aussi l'association importante entre la victimisation et le fonctionnement psychologique (ex. : anxiété, dépression, agression, stress posttraumatique). Les conséquences théoriques et pratiques pour la prévention de la victimisation en enfance sont discutées.

Mots clés : victimisation en enfance, cooccurrence, programmes de prévention

\section{VICTIMIZATION}

There are many different forms of victimization, including maltreatment (i.e., caregiver-perpetrated physical, emotional, or sexual abuse; neglect), exposure to family violence (i.e., intimate partner violence), sexual victimization (i.e., noncaregiver-perpetrated sexual assault), peer and/or sibling victimization (i.e., physical or emotional bullying; gang assaults), Internet victimization (e.g., cyber-bullying), conventional crimes (e.g., property crimes such as robbery, theft, or vandalism), and witness/indirect victimization (e.g., exposure to community violence) (Hamby \& Grych, 2013). Children (ages 0-18) are the most criminally victimized segment of our population (Finkelhor, 2009), and research has demonstrated that most victimized children tend to experience multiple victimization (Cyr, Clément, \& Chamberland, 2013; Gannon \& Mihorean, 2005; Turner, Finkelhor, \& Ormrod, 2010), defined as exposure to different types of victimization within the same time period (Finkelhor, Ormrod, Turner, \& Hamby, 2005). Multiple victimization, including more severe multiple victimization known as poly-victimization (often referring to the top $10^{\text {th }}$ percentile of multiple victims in a study sample), differs from chronic victimization, in which a child is repeatedly exposed to the same type of victimization, and from single victimization, in which a child is exposed to one victimization type in the same incident (Finkelhor, Ormrod, \& Turner, 2007a).

Multiple victimization has been established as the rule, rather than the exception, with research indicating that among victimized children, approximately 6.5 in 10 have experienced multiple victimization in the past year alone (Finkelhor, Turner, Hamby, \& Ormrod, 2011). Cyr et al. (2012); Cyr, Clément, and Chamberland, 2013; and Cyr, Chamberland, Clément, Lessard, et al., 2013) have been the first to publish multiple victimization data from both clinical and community samples in Canada. In a population design study, Cyr, Clément, and Chamberland (2013) examined the victimization experiences of a randomly selected sample of 1,401 caregivers of children ages two to 11 living in the province of Quebec, Canada. Findings indicated that $68 \%$ of the sample experienced at least one lifetime victimization experience, and that $42 \%$ experienced multiple victimization. Lifetime victimization rates were found to increase with age, with one in four children aged six to 11 years experiencing more than four victimization types during their lifetime. In an additional research project, Cyr, Chamberland, Clément, Lessard, et al. (2013) examined the victimization experience of 1,411 children from Quebec and provided victimization data on a subsample of 797 school-aged children (aged six to 11 years). Results revealed that children aged six to 11 were exposed to an average of 2.9 victimization experiences in their lifetime, and that a notable portion of these children experienced physical assaults (49.8\%), property victimization $(35.3 \%)$, witness or indirect victimization (24.0\%), maltreatment (10.8\%), and sexual victimization (6.2\%) over their lifetime.

The toll of multiple victimization on children can be truly devastating across multiple domains of functioning. Associations between multiple victimization and such outcomes as aggression, academic functioning, depression, and trauma symptoms have been consistently noted in the literature (Cyr, Clément, \& 
Chamberland, 2013; Finkelhor, 2009; Holt, Finkelhor, \& Kantor, 2007; Nishina \& Juvonen, 2005; Romano, Babchishin, Marquis, \& Fréchette, in press; Saunders, 2003; Stevens, Ruggerio, Kilpatrick, Resnick, \& Saunders, 2005). Of note, exposure to victimization in one context, such as maltreatment, increases the risk for exposure to additional forms of victimization (e.g., sexual victimization, conventional crimes). It is not surprising that multiply victimized children have been found to have higher levels of psychosocial difficulties compared to children exposed to a single episode of victimization or to chronic victimization of a single type (Cyr, Clément, \& Chamberland, 2013; Finkelhor, Ormrod, \& Turner, 2009; Hamby \& Grych, 2013; Holt et al., 2007; Stevens et al., 2005; Turner et al., 2010). Furthermore, the impact of multiple victimization appears to be independent of children's prior psychological difficulties or prior victimization exposure (Boney-McCoy \& Finkelhor, 1996; Finkelhor, 2009).

Not only is multiple victimization associated with a range of psychosocial difficulties, but it has also been found to persist over time. Finkelhor, Ormrod, and Turner (2007b) found that children who experienced three or more types of victimization in the past year were five times more likely to continue to experience multiple victimization one year later. Multiple victimization has also been found to increase the likelihood of a variety of nonvictimization adverse life events, such as accidents or losses. This is especially true for children with numerous multiple victimization experiences (i.e., poly-victims), with research indicating that these children have 4.7 additional adversities, compared to 2.1 for nonpoly-victims (Finkelhor et al., 2011).

Recent multiple victimization research has begun to document different forms of victimization that commonly occur together. For example, in a nationally representative U.S. study, Finkelhor, Turner, et al. (2009) found that lifetime exposure to victimization was associated with a two- to three-fold increased risk of exposure to additional types of victimization. Of note, these authors found that sexual victimization and maltreatment were particularly associated with additional victimization forms, even after controlling for differences in outcome incidence (i.e., base rates). Maltreatment, for example, was associated with an approximately three-fold increase in exposure to lifetime sexual victimization and property crimes, as well as an approximate five-fold increase in sexual victimization and physical assaults. In addition, research has found that poly-victimized children are more likely to report sexual victimization and maltreatment (Finkelhor et al., 2007a). The co-occurrence among victimization experiences has been found to be more prominent in clinical samples (Saunders, 2003). For example, Cyr and colleagues (2012) examined the victimization experiences of 220 two- to 17-year-olds from Quebec who were involved in the child welfare system. Findings indicated that $93 \%$ had experienced multiple victimization in the past year alone, with exposure to an average of 3.3 victimization types. In short, it appears that adversities, including victimizations, do not tend to be randomly distributed, but rather to interact and vary in relation to specific individual (e.g., child age, sex) and systemic factors (e.g., family substance abuse) (Hamby \& Grych, 2013).

The sources of the co-occurrence among certain victimization experiences have been posited to be shared etiological pathways and contextual factors, such as cognitive processes within the child as well as attachment relationships (Grych \& Swan, 2012). The ecological perspective is a helpful theoretical framework because it acknowledges the dynamic and complex nature of childhood victimization. This framework emphasizes that the various systems (e.g., family, neighbourhood) within which a child is embedded, along with characteristics of the child, interact with and build upon one another to determine victimization risk and outcomes (Cicchetti \& Lynch, 1993). Further, this framework acknowledges that victimization occurs 
within a dynamic and interactional context of adversity (Hamby \& Grych, 2013). The ecological framework, therefore, encourages a more holistic evaluation of victimization, shifting the focus from specific victimization experiences to the various contexts in which these experiences occur (Hooven, Nurius, Logan-Greene, \& Thompson, 2012).

Research examining the interconnections that exist among victimization experiences is essential. Indeed, it has been argued that "for etiological models of interpersonal violence to be accurate, it will be critical to understand which forms of abuse, maltreatment, and trauma are most closely related and why" (Hamby \& Grych, 2013, p. 105). Research that recognizes and explores the co-occurrence among childhood victimization experiences might help expand our knowledge of the developmental and contextual factors that are associated with childhood victimization, and more generally, would allow for a more accurate and nuanced portrait of the phenomenon (Finkelhor, 2009). The field of multiple victimization has significant implications for the prevention of childhood victimization, as it could help guide more comprehensive and integrated approaches to program development (Hamby \& Grych, 2013). Indeed, Finkelhor (2009) has noted that the vast majority of prevention programs tend to target specific victimization forms in isolation from one another (e.g., bullying, maltreatment). While important and praiseworthy, these programs fail to account for the unfortunate reality that victimized children, in particular those exposed to sexual victimization and maltreatment, are often victimized in additional and different contexts. Grych and Swan (2012) argue that prevention programs that do not account for the interconnection among victimization forms may be less effective than programs that recognize and address the co-occurrences among victimization forms (e.g., a bullying prevention program that also accounts for potential modelling from exposure to intimate partner violence).

The aim of the current study was to build on existing knowledge in the area of childhood multiple victimization. Past research has tended to focus on U.S. samples that cover a broad developmental period (two to 17 years old). Given that children of varying ages often react quite differently to victimization (Finkelhor, 2009; Finkelhor \& Dziuba-Leatherman, 1995), this study focused on school-aged children, a population that is often overlooked in epidemological studies of victimization (Finkelhor \& Hashima, 2001; Turner et al., 2012). A comprehensive range of victimization experiences was examined, namely 46 types that can be grouped into the seven following forms: (a) peer and/or sibling victimization; (b) conventional victimization (i.e., property crimes); (c) sexual victimization (noncaregiver-perpetrated); (d) indirect/witness victimization; (e) maltreatment; (f) exposure to family violence; and (g) Internet victimization. The objective of the current study was to determine the frequency of caregiver-reported victimization, the co-occurrence of different victimization forms, and the psychosocial correlates of multiple victimization in a sample of 213 children aged six to 12 years.

\section{METHODS}

\section{Participants}

To be included in the study, caregivers were required to: (a) have a child between six and 12 years of age; (b) live in the Ottawa/Gatineau (Canada) area; (c) be fluent in English; (d) have access to a computer with an Internet connection; (e) not have a partner who has already completed this study on either the same child or on another child living in the same household (this exclusion criteria was required to ensure independence of 
data); and (f) be between 18 and 59 years of age. If caregivers had more than one child in the prescribed age range, they were asked to respond to study questions with regard to the child with the most recent birthday.

Participants included 213 caregivers with an average age of 38.75 years $(S D=6.25)$ and with children who, on average, were $8.04(S D=1.97)$ years of age. Participants were primarily female $(90.1 \%)$, and the majority of households were comprised of two biological parents $(93.0 \%)$. Of the $20.2 \%$ of caregivers who were divorced, approximately half (51.2\%) had full custody of the study child, while the remaining 48.8\% reported having shared custody. As illustrated in Table 1, the proportion of girls and boys in the sample was evenly distributed (47.4\% and 52.6\%, respectively), and the children were primarily Caucasian (79.3\%). The average household size was 4.5 , with approximately $36.0 \%$ of children in the sample having older siblings $(M=0.52, S D=0.79)$. Most caregivers in the sample, as well as their spouses, had postsecondary education ( $85.0 \%$ and $79.2 \%$, respectively). Finally, the median household income before tax was between $\$ 100,000$ and $\$ 109,999$.

In comparison with data from the Canadian Census and the National Household Survey (NHS), the obtained sample was appropriately representative of individuals from the Ottawa/Gatineau area. Indeed, according to the most recent NHS data (Statistics Canada, 2012a), the average family income in Ottawa is $\$ 99,880$. In the current sample, data on income was normally distributed with a sample average between $\$ 90$ and $\$ 109,999$. The ethnic and family composition distribution obtained in the current study was also similar to census data reported by Statistics Canada. For example, visible minorities represent approximately $22.8 \%$ of the Ottawa/Gatineau population, and approximately $67.0 \%$ of census families are married (Statistics Canada, 2012b; 2013). Comparatively, visible minorities represented $20.7 \%$ of our participants, and $68.1 \%$ of our sample were married. The level of educational attainment was slightly higher in the study sample, compared to census data. While according to the 2011 NHS survey, $44.3 \%$ of adults in the Ottawa/Gatineau area have a university degree (Statistics Canada, 2013), 54.7\% of caregivers in the study (including the respondent and their spouse) had a university degree.

\section{Measures}

Socio-demographics. Caregivers provided information on their sex, age, ethnicity, highest level of completed education, number of children (and their ages) living in the home, family status, and household income before taxes. Further, caregivers provided information on each child's age, sex, and ethnicity, as well as information on their relationship to the child (i.e., adoptive parent, biological parent) and current custody status.

Victimization experiences. The caregiver-reported version of the Juvenile Victimization Questionnaire - Revised (JVQ-CR-R1) (Finkelhor, Turner, et al., 2009) was used to assess a comprehensive range of victimizations. The JVQ-CR-R1 is a 46-item measure that assesses the following victimization experiences: (a) child maltreatment (e.g., caregiver-perpetrated abuse); (b) conventional crime (e.g., having something stolen); (c) peer/sibling victimization (e.g., being hit by a peer); (d) sexual victimization (e.g., noncaregiver-perpetrated sexual assault); (e) witnessing/indirect victimization (e.g., exposure to community violence); (f) exposure to family violence (e.g., intimate partner violence); (g) Internet victimization (e.g., cyber-bullying). The JVQ-CR-R1 is an enhanced version of the initial JVQ-CR (Hamby, Finkelhor, 
Table 1

Sample Description

\begin{tabular}{|c|c|c|}
\hline & $\%$ & $n$ \\
\hline Age of child ${ }^{a}$ & $8.0(2.0)$ & - \\
\hline \multicolumn{3}{|l|}{ Sex of child } \\
\hline Boys & 52.6 & 112 \\
\hline Girls & 47.4 & 101 \\
\hline \multicolumn{3}{|l|}{ Ethnicity of child } \\
\hline European/Caucasian & 79.3 & 169 \\
\hline African & 1.0 & 2 \\
\hline Asian & 1.0 & 2 \\
\hline Middle Eastern & 2.3 & 5 \\
\hline First Nations & 2.8 & 6 \\
\hline Hispanic & 1.4 & 3 \\
\hline Mixed & 12.2 & 26 \\
\hline Household size ${ }^{a}$ & $4.5(1.2)$ & - \\
\hline Older sibling(s) & 36.2 & 77 \\
\hline \multicolumn{3}{|l|}{ Family structure } \\
\hline Married & 68.1 & 145 \\
\hline Cohabiting & 10.8 & 23 \\
\hline Single & 6.6 & 14 \\
\hline Stepfamily & 14.5 & 31 \\
\hline \multicolumn{3}{|l|}{ Caregiver's education } \\
\hline High school & 15.0 & 32 \\
\hline College & 25.4 & 54 \\
\hline Bachelor's/undergraduate degree & 39.4 & 84 \\
\hline Master's degree & 14.1 & 30 \\
\hline Doctoral degree & 3.8 & 8 \\
\hline $\begin{array}{l}\text { Professional degree (e.g., law, medicine, } \\
\text { veterinary medicine) }\end{array}$ & 2.3 & 5 \\
\hline \multicolumn{3}{|l|}{ Spouse's education ${ }^{\mathrm{b}}$} \\
\hline High school & 20.8 & 43 \\
\hline College & 29.5 & 61 \\
\hline Bachelor's/undergraduate degree & 30.8 & 64 \\
\hline Master's degree & 14.0 & 29 \\
\hline Doctoral degree & 3.9 & 8 \\
\hline $\begin{array}{l}\text { Professional degree (e.g., law, medicine, } \\
\text { veterinary medicine) }\end{array}$ & 1.0 & 2 \\
\hline \multicolumn{3}{|l|}{ Household income ( $\$$ before tax $)$} \\
\hline Less than 19,999 & 0.9 & 2 \\
\hline $20-49,999$ & 12.7 & 27 \\
\hline $50-79,999$ & 15.5 & 33 \\
\hline $80-109,999$ & 25.9 & 55 \\
\hline $110-119,999$ & 20.2 & 43 \\
\hline Over 140,000 & 24.8 & 53 \\
\hline
\end{tabular}

Note.

${ }^{a}$ Mean (standard deviations).

${ }^{\mathrm{b}}$ Applicable in $97.2 \%$ of cases $(N=207)$. 
Ormrod, \& Turner, 2005), with 14 additional items that further assess exposure to family violence, witnessing/indirect victimization violence, and Internet victimization (Turner et al., 2010). The JVQ asks caregivers to indicate whether or not their child had experienced a range of victimization experiences either in the past year and/or in his/her lifetime.

The JVQ-CR has been found to have excellent test-retest reliability over a 3-4 week period $(r=.95)$ and good internal consistency ( $\alpha=.80$; Finkelhor, Hamby, Ormrod, \& Turner, 2005). An internal consistency alpha of .86 was found in the current sample. As the JVQ conceptualizes victimization experiences by using concrete behavioural terms, it has been asserted that this measure is less vulnerable to interpretation biases (Hamby et al., 2005).

Psychosocial functioning. The Trauma Symptom Checklist for Young Children (TSCYC) is a caregiverreported measure of internalizing and externalizing symptoms for three- to 12-year-olds (TSCYC; Briere, 2005). Caregivers respond to 90 items on a Likert-type scale, ranging from 0 (not at all) to 4 (very often). The TSCYC contains two validity scales and nine clinical. In the current study, we focused on scales measuring posttraumatic stress as well as internalizing and externalizing difficulties, namely (a) Posttraumatic Stress Total; (b) Depression; (c) Anxiety; and (d) Anger/Aggression. The discriminant, predictive, and content validity of the TSCYC have been demonstrated through numerous studies (Briere, 2005; Briere et al., 2001). Further, the internal consistency values for the clinical scales in our sample ranged from good to excellent $(\alpha=.76$ to $\alpha=.91)$.

\section{Procedure}

Ethics approval was obtained from the Faculty of Social Sciences Research Ethics Board of the University of Ottawa. Diverse strategies were used to recruit participants, including posting study notices in paediatricians' offices, as well as in libraries, various community centres, and mental health centres specializing in children. Interested individuals were able log onto the survey Web site (fluidsurveys.com) using the Web link provided on the study notice. At this time, inclusion and exclusion criteria were assessed through a series of questions. If the participants answered "no" to any inclusion criteria, they were forwarded to a Web page that thanked them for their interest and explained that they were not eligible for the study. If participants were eligible for the study, the consent form was provided online, and once consent was obtained, participants were able to begin the study. A link to a document with a list of psychological resources was provided on each Web page throughout the study in the event that individuals experienced distress as a result of study participation and/or wished to obtain information on psychological resources for their child.

The online study required approximately 30 minutes to complete. No identifiable information was collected from the caregiver (e.g., IP address). Further, to ensure participant anonymity, cookies were not installed on participants' computers. This autonomous Internet design was used in an attempt to gain more accurate victimization rates by minimizing socially desirable responding (in particular for maltreatment reports) or nondisclosure due to fear of reprisal (e.g., involvement of child protection). Specifically, the anonymous Internet design circumvented ethical issues surrounding researchers' duty to report children in need of protection as there was no way to identify participants. 


\section{Plan of Analysis}

For the first objective, the frequency of exposure to the 46 victimization types for lifetime was calculated. In addition, the frequency of lifetime exposure to seven forms of victimization (i.e., conventional crimes, sexual victimization, maltreatment, indirect/witness victimization, peer and/or sibling victimization, Internet victimization, exposure to family violence and abuse) was calculated. A series of chi-squared analyses were conducted to identify sex differences on exposure to lifetime victimization forms, multiple victimization status, and poly-victimization status. Note that both multiple- and poly-victimization statuses were based only on data from five victimization forms. This is because the classification method for multiple- and polyvictimization established in the literature stems from the initial version of the JVQ (34-item version), which did not include Internet victimization and exposure to family violence.

The second objective was to examine co-occurrence among the seven victimization forms by way of a series of cross-tabulations to establish the percentage of children with one form of victimization who also experienced additional forms. These analyses helped to elucidate the general overlap between victimization forms.

The third objective examined associations between various victimization experiences and children's psychological difficulties by way of linear regressions. The regression models controlled for a series of socio-demographic variables (i.e., age, sex, ethnicity, household size and income, and parental education). The associations between lifetime victimization and psychological difficulties were also plotted to illustrate the nature of the association.

\section{RESULTS}

\section{Frequency of Lifetime Victimization}

Almost all six- to12-year-olds in the sample (97.2\%) were reported to have been exposed to at least one type of victimization during their lifetime. Table 2 indicates that the majority of children $(86.9 \%)$ in our sample had experienced two or more types of victimization (i.e., multiple victimization) during their lifetime, and that $10.8 \%$ could be categorized as lifetime poly-victims, ${ }^{1}$ using thresholds suggested by Finkelhor, Ormrod, Turner, and Holt (2009). In fact, victimized children were reported by caregivers to have been exposed to an average of $6.58(S D=5.21$, range $=0-31)$ victimizations in their lifetime, and of these victimizations, an average of $4.10(\mathrm{SD}=2.83)$ are classified as direct victimization (i.e., child is directly involved as opposed to witnessing violence). The most common victimization form experienced by the sample was peer and/ or sibling victimization (83.6\%), followed by conventional crimes $(73.7 \%)$, witness/indirect victimization (43.7\%), exposure to family violence $(32.4 \%)$, maltreatment $(27.7 \%)$, sexual victimization $(9.4 \%)$, and Internet victimization $(6.1 \%)$.

Turning to sex differences, Table 2 indicates that boys were reported by caregivers to have experienced a slightly greater number of lifetime victimizations than girls $(t=-2.19, p<.05)$, with an average of 7.09 victimizations $(S D=5.35)$ for boys and 5.61 victimizations $(S D=5.05)$ for girls. There were no statistically significant sex differences in multiple- and poly-victimization status, but there was a trend suggesting that boys more often experienced multiple and poly-victimization, compared to girls. There were no statistically significant sex differences based on victimization forms, with the exception of exposure to family violence 
Table 2

Lifetime Victimization Rates

\begin{tabular}{|c|c|c|c|c|}
\hline & \multicolumn{4}{|c|}{ Lifetime } \\
\hline & $\begin{array}{c}\text { Total } \\
\%\end{array}$ & $\begin{array}{c}\text { Boys } \\
\%\end{array}$ & $\begin{array}{c}\text { Girls } \\
\%\end{array}$ & $X^{2}$ \\
\hline Multiple Victimization ${ }^{\mathrm{a}}$ & 86.9 & 90.2 & 83.2 & $2.29 \mathrm{t}$ \\
\hline Poly-Victimization ${ }^{\mathrm{b}}$ & 10.8 & 14.3 & 6.9 & $2.98 t$ \\
\hline Any Conventional Crime & $\mathbf{7 3 . 7}$ & 75.9 & 71.3 & 0.58 \\
\hline Any Physical Assault & 82.6 & 88.4 & 76.2 & $5.46^{*}$ \\
\hline Assault with a weapon & 12.2 & 18.8 & 5.0 & $9.44 * * *$ \\
\hline Assault without a weapon & 42.3 & 50.0 & 33.7 & $5.81 * *$ \\
\hline Attempted assault & 7.5 & 9.8 & 5.0 & 1.81 \\
\hline Kidnapping & 1.4 & 1.8 & 1.0 & 0.24 \\
\hline Bias attack & 4.2 & 4.5 & 4.0 & 0.03 \\
\hline Any Property Crimes & 60.1 & 58.0 & 62.4 & 0.42 \\
\hline Robbery & 37.6 & 35.7 & 39.6 & 0.34 \\
\hline Theft & 17.4 & 23.2 & 10.9 & $5.62 * *$ \\
\hline Vandalism & 37.1 & 33.9 & 40.6 & 1.01 \\
\hline Any Maltreatment & 27.7 & 32.1 & 22.8 & $2.34 t$ \\
\hline Physical abuse & 11.3 & 13.4 & 8.9 & 1.07 \\
\hline Psychological/emotional abuse & 18.8 & 24.1 & 12.9 & $4.40^{*}$ \\
\hline Neglect & 2.3 & 2.7 & 2.0 & 0.11 \\
\hline Custodial interference & 5.2 & 3.6 & 6.9 & 1.22 \\
\hline Any Peer and/or Sibling Victimization & 83.6 & 84.8 & 82.2 & 0.27 \\
\hline Gang/group assault & 5.6 & 7.1 & 4.0 & 1.01 \\
\hline Peer/sibling assault & 74.2 & 75.0 & 73.3 & 0.08 \\
\hline Genital assault & 13.6 & 25.0 & 1.0 & $26.03 * * *$ \\
\hline Bullying & 31.5 & 32.1 & 30.7 & 0.05 \\
\hline Emotional bullying & 45.1 & 47.3 & 42.6 & 0.48 \\
\hline Dating violence & 0.9 & 0.9 & 1.0 & 0.01 \\
\hline Any Sexual Victimization & 9.4 & 9.9 & 8.9 & 0.06 \\
\hline Any sexual assault & 2.8 & 4.0 & 1.8 & 0.92 \\
\hline By a known adult & 0.0 & 0.0 & 0.0 & - \\
\hline By a nonspecified adult & 0.0 & 0.0 & 0.0 & - \\
\hline By a peer & 2.8 & 4.0 & 1.8 & 0.92 \\
\hline Rape, completed/attempted & 0.0 & 0.0 & 0.0 & - \\
\hline Sexual exposure/flashing & 5.6 & 6.3 & 5.0 & 0.17 \\
\hline Sexual harassment & 1.9 & 1.8 & 2.0 & 0.01 \\
\hline Sexual misconduct/statutory rape & 0.9 & 0.9 & 1.0 & 0.01 \\
\hline
\end{tabular}




\begin{tabular}{|c|c|c|c|c|}
\hline \multicolumn{5}{|c|}{$\begin{array}{c}\text { Table } 2 \\
\text { (continued) }\end{array}$} \\
\hline & \multicolumn{4}{|c|}{ Lifetime } \\
\hline & $\begin{array}{c}\text { Total } \\
\%\end{array}$ & $\begin{array}{c}\text { Boys } \\
\%\end{array}$ & $\begin{array}{c}\text { Girls } \\
\%\end{array}$ & $X^{2}$ \\
\hline Any Witnessing/Indirect Victimization & 43.7 & 46.4 & 40.6 & 0.74 \\
\hline Witnessed an assault with a weapon & 8.5 & 8.0 & 8.9 & 0.05 \\
\hline Witnessed an assault without a weapon & 22.1 & 23.2 & 20.8 & 0.18 \\
\hline Someone close murdered & 4.7 & 3.6 & 5.9 & 0.67 \\
\hline Saw a murder & 5.6 & 7.1 & 4.0 & 1.01 \\
\hline Exposed to shooting, bombs and/or riots & 1.9 & 0.9 & 3.0 & 1.24 \\
\hline In a war zone & 3.3 & 5.9 & 0.9 & $4.26^{*}$ \\
\hline Internet Victimization & 6.1 & 6.9 & 5.4 & 0.23 \\
\hline Cyber bullying & 5.2 & 5.9 & 4.5 & 0.24 \\
\hline Sexual harassment & 1.4 & 0.9 & 2.0 & 0.45 \\
\hline Exposure to Family Violence & 32.4 & 38.4 & 25.7 & 3.88* \\
\hline Parent threatened to hurt other parent & 5.6 & 7.1 & 4.0 & 1.01 \\
\hline Parent broke/punched object & 21.6 & 24.1 & 18.8 & 0.88 \\
\hline Parent pushed other parent & 12.2 & 14.3 & 9.9 & 0.95 \\
\hline Parent hit/slapped other parent & 7.5 & 9.8 & 5.0 & 1.81 \\
\hline Parent kicked/choked or beat up other parent & 3.8 & 3.6 & 4.0 & 0.02 \\
\hline Grown-up/teen pushed, hit or beat up other & 7.5 & 4.5 & 10.9 & $3.16^{* *}$ \\
\hline
\end{tabular}

Note.

${ }^{a}$ Exposure to two or more victimization types, excluding the supplemental JVQ scales (i.e., Internet victimization and exposure to family violence), to allow for comparison of results.

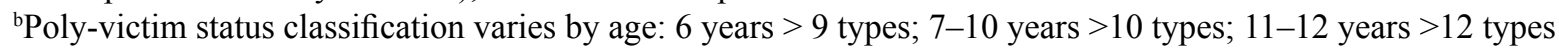
(Finkelhor, Ormrod, Turner, \& Holt, 2009).

$* * * p<.001 . * * p<.01 . * p<.05 ; t p<.10$.

and physical assaults (subscale of conventional crimes). For exposure to family violence, boys were reported to have greater exposure than girls $\left(38.4 \%\right.$ vs. $\left.25.7 \% ; \chi^{2}=3.88, p<.05\right)$. For physical assaults, boys also experienced greater exposure than girls $\left(88.4 \%\right.$ and $76.2 \%$, respectively; $\left.\chi^{2}=5.46, p<.05\right)$. Finally, there was a statistical trend for school-aged boys to experience more maltreatment than girls $(32.1 \%$ and $22.8 \%$, respectively).

Turning to victimization types, boys were more frequently exposed to the following, compared to girls: (a) assault with a weapon $\left(\chi^{2}=5.46, p<.05\right)$; (b) assault without a weapon $\left(\chi^{2}=9.44, p<.001\right)$; (c) attempted assault $\left(\chi^{2}=5.81, p<.01\right)$; (d) theft $\left(\chi^{2}=5.62, p<.01\right)$; (e) psychological and emotional maltreatment $\left(\chi^{2}=\right.$ $4.40, p<.05$ ); (f) genital assault $\left(\chi^{2}=26.03, p<.001\right.$ ); and (g) exposure to a war zone $\left(\chi^{2}=4.26, p<.05\right.$ ). Girls, on the other hand, were found to more frequently witness a grown-up/teen push, hit, or beat up another grown-up/teen $\left(\chi^{2}=3.16, p<.01\right)$, compared to boys. 


\section{Co-occurrence among Victimization Forms}

Among children who were reported to have experienced at least one type of victimization during their lifetime $(n=207), 17.4 \%$ had no additional experiences. In contrast, $25.8 \%$ were exposed to two forms of victimization, $23.9 \%$ were exposed to three forms, $16.0 \%$ were exposed to four forms, and $14.1 \%$ were exposed to five or more forms. Table 3 presents the percentage of children exposed to one form of victimization who were also exposed to additional forms in their lifetime. Findings indicate considerable overlap among victimization forms, in particular for sexual victimization, Internet victimization, and maltreatment. Indeed, while these more "severe" forms of victimization were less prevalent in the sample, Table 3 illustrates that they tended to cluster together (i.e., exposure to one of these more severe forms was often associated to exposure to an additional one of these forms). Internet victimization, compared to other victimization forms, had the highest percentage of children who also experienced sexual victimization (23.1\%) and maltreatment (53.8\%). In addition, children exposed to sexual victimization had the highest rate of exposure to Internet victimization (15.0\%). More commonly occurring victimization forms were less related to severe victimizations. For example, while only $10.7 \%$ children exposed to peer and/or sibling victimization also experienced sexual victimization, $95.0 \%$ of children who experienced sexual victimization also experienced peer and/ or sibling victimization. Table 3 also illustrates that children with any victimization exposure, regardless of victimization form, tended to also experience conventional crimes (Range $=88.2 \%-100 \%$ ) and peer and/ or sibling victimization $(73.9 \%-90 \%)$.

Table 3

Overlap across Lifetime Victimization Forms

\begin{tabular}{|c|c|c|c|c|c|c|c|}
\hline & \multicolumn{7}{|c|}{ Percentage matched } \\
\hline & $\begin{array}{c}\begin{array}{c}\text { Any } \\
\text { maltreatment }\end{array} \\
n=59\end{array}$ & $\begin{array}{l}\text { Any } \\
\text { sexual } \\
n=20\end{array}$ & $\begin{array}{l}\text { Any peer } \\
\text { and/or } \\
\text { sibling } \\
n=178\end{array}$ & $\begin{array}{c}\text { Any } \\
\text { witness/ } \\
\text { indirect } \\
n=93\end{array}$ & $\begin{array}{c}\begin{array}{c}\text { Any } \\
\text { conventional } \\
n=157\end{array}\end{array}$ & $\begin{array}{c}\text { Any exposure } \\
\text { to family } \\
\text { violence } \\
n=69\end{array}$ & $\begin{array}{c}\text { Any } \\
\text { Internet } \\
n=13\end{array}$ \\
\hline Any maltreatment & - & 35.0 & 30.9 & 38.7 & 31.8 & 44.9 & 53.8 \\
\hline Any sexual & 11.9 & - & 10.7 & 14.0 & 11.5 & 14.5 & 23.1 \\
\hline $\begin{array}{l}\text { Any peer and/or } \\
\text { sibling }\end{array}$ & 93.2 & 95.0 & - & 88.2 & 87.9 & 88.4 & 100 \\
\hline $\begin{array}{l}\text { Any witness/ } \\
\text { indirect }\end{array}$ & 61.0 & 65.0 & 46.1 & - & 52.9 & 63.8 & 46.2 \\
\hline Any conventional & 84.7 & 90.0 & 77.5 & 89.2 & - & 73.9 & 76.9 \\
\hline $\begin{array}{l}\text { Any exposure to } \\
\text { family violence }\end{array}$ & 52.5 & 50.0 & 34.3 & 47.4 & 32.5 & - & 30.8 \\
\hline Any Internet & 11.9 & 15.0 & 7.3 & 6.5 & 6.4 & 5.8 & - \\
\hline
\end{tabular}

Note. Table should be interpreted as follows: values represent the number children with a given victimization form, as indicated in the top row of the table, who also experienced the forms identified on the left column of the table. For example, of the children with any maltreatment experiences, $11.9 \%$ also experienced sexual victimization. However, of the children with sexual victimization, $35 \%$ also have maltreatment. 
As illustrated in Table 3, maltreatment and exposure to family violence commonly co-occurred with one another: $52.5 \%$ of children who experienced maltreatment also experienced exposure to family violence, and $44.9 \%$ of children who experienced family violence also experienced maltreatment. Furthermore, maltreatment and exposure to family violence were often associated with exposure to peer and/or sibling victimization. For example, out of the 59 children who experienced maltreatment, 93.2\% also experienced peer and/or sibling victimization. In addition, out of the 69 children who experienced family violence, all of them also experienced peer and/or sibling victimization. However, out of the 178 children who experienced peer and/or sibling victimization, only approximately one-third also experienced maltreatment $(30.9 \%)$ or family violence $(34.3 \%)$.

\section{Psychosocial Correlates of Multiple Victimization}

A series of linear regressions were conducted to examine the relationship between multiple victimization and psychosocial difficulties, controlling for socio-demographic factors and past-year victimization exposure. In these models, the higher the number of lifetime victimization experiences, the greater the number of posttraumatic symptoms $(B=.36 ; p<.05)$, anxiety $(B=.33 ; p<.001)$, depression $(B=.27 ; p<.001)$, and aggression/anger $(B=.29 ; p<.001)$. Figures $1-4$ further illustrate the association between lifetime exposure to victimization and psychological difficulties. Findings indicate a linear or dose-response relationship between lifetime victimizations and psychosocial symptoms. Specifically, as exposure to victimization increases, the figures illustrate that psychosocial symptoms also increase and that children with the greatest number of victimizations, which represent a minority of the overall sample, are generally represented in the top distribution of psychosocial symptoms scores.

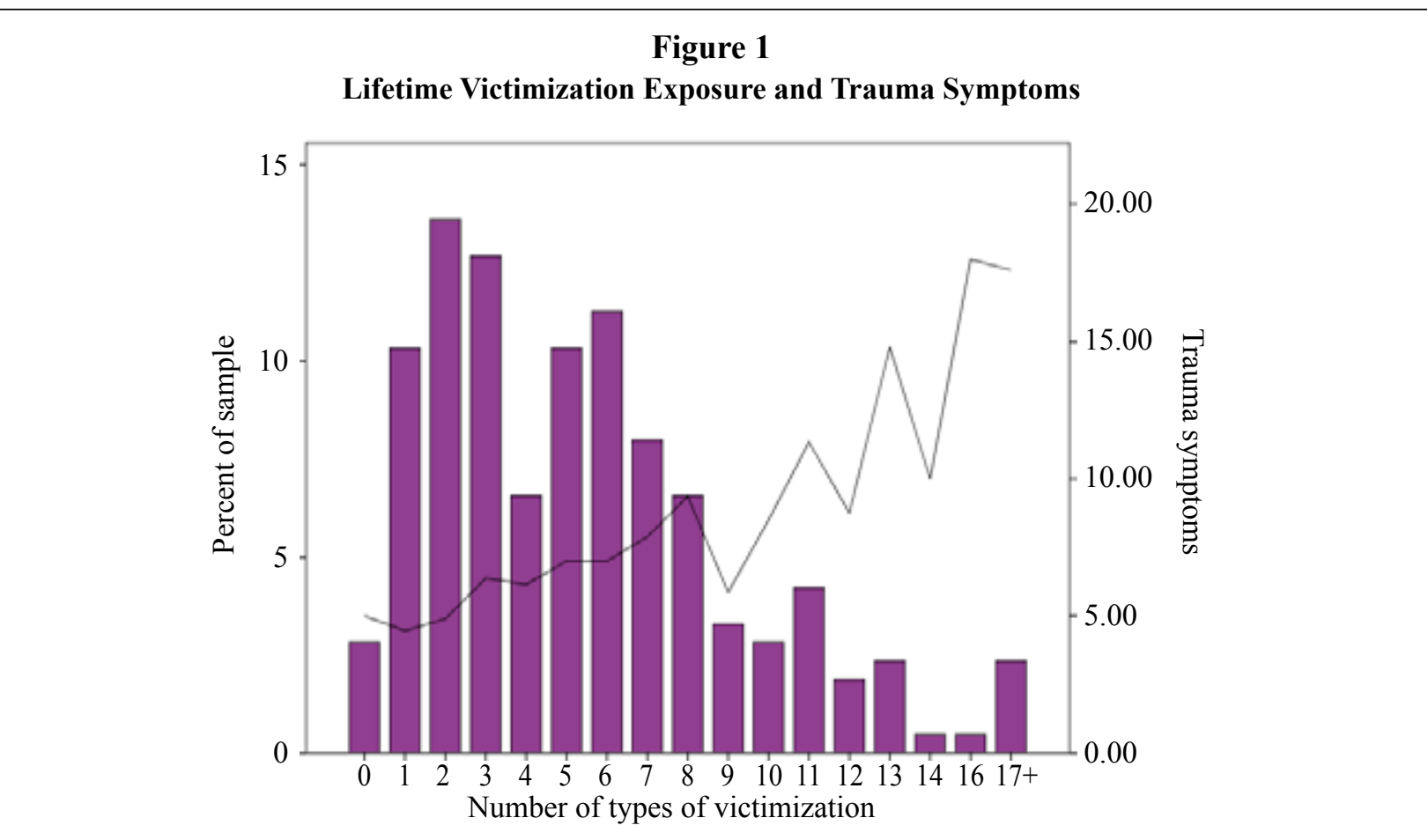

Note. Bars represent lifetime victimization exposure, and the solid black line is mean symptom score. 
Figure 2

Lifetime Victimization Exposure and Depressive Symptoms

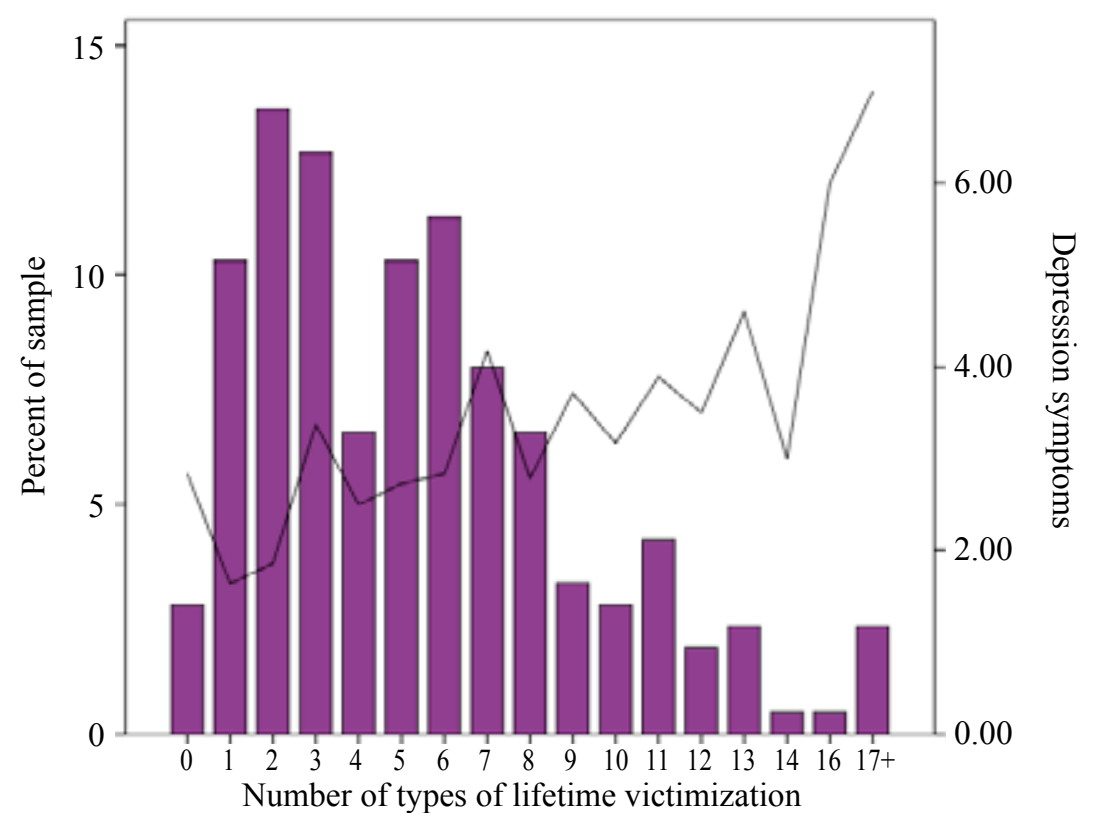

Note. Bars represent lifetime victimization exposure, and the solid black line is mean symptom score.

Figure 3

Lifetime Victimization Exposure and Anxiety Symptoms

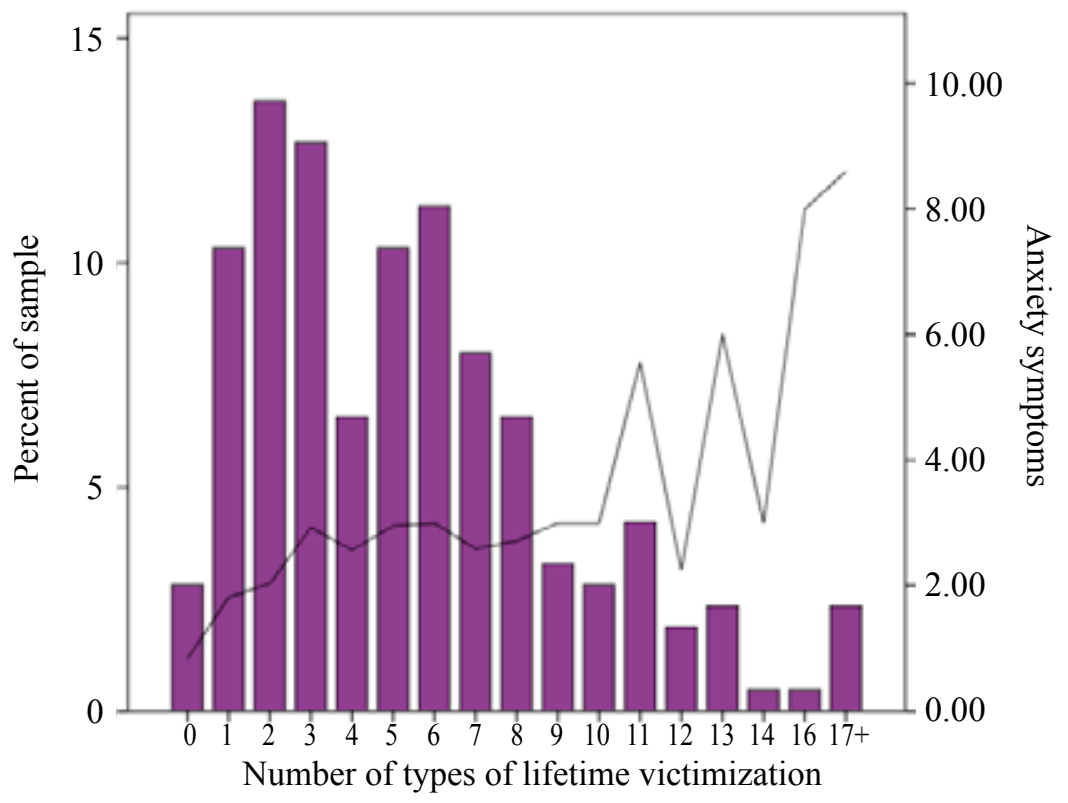

Note. Bars represent lifetime victimization exposure, and the solid black line is mean symptom score. 
Figure 4

Lifetime Victimization Exposure and Anger/Aggression Symptoms

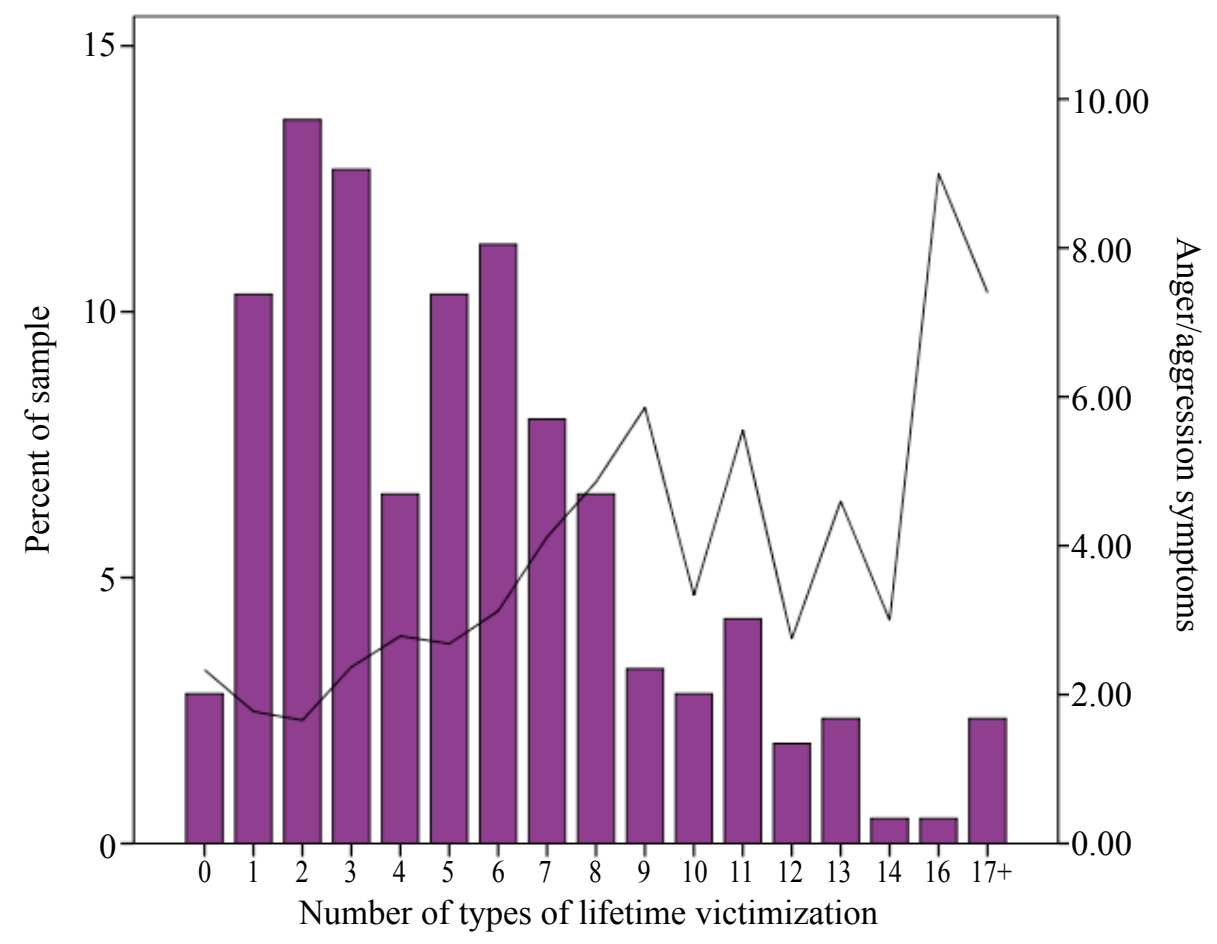

Note. Bars represent lifetime victimization exposure and the solid black line is mean symptom score.

\section{DISCUSSION}

The current study was designed to add new knowledge in the area of childhood multiple victimization, which aims to examine the full spectrum of victimizations that could be experienced by children across time and in various contexts. This is a notable contrast to the majority of scientific inquiry on childhood victimization to date, which has tended to examine different types of victimization in isolation from one another and to formulate specific and separate theories of risk accordingly (Hamby \& Grych, 2013). This approach has contributed significantly to the field by forming the foundation of our understanding on childhood victimization. However, it is inherently problematic as research has found that most victimized children are multiply victimized and that victimization exposure across multiple contexts exerts a greater impact (both in terms of psychological outcomes and future risk for victimization) than any single type of victimization (Finkelhor et al., 2007a; Finkelhor, Ormrod, \& Turner, 2007c; Hamby \& Grych, 2013).

Findings from the current study lend support to the ubiquitous nature of childhood multiple victimization, as a number of children were reported by caregivers to have been exposed to high levels of victimization, 
and the majority experienced multiple victimization. While boys tended to be exposed to more victimizations than girls, both girls and boys tended to be exposed to similar forms of victimization, with the exception of exposure to family violence and the conventional crimes subscale of physical assault (where exposure was higher for boys). Some sex-based differences, however, were found among exposure to victimization types, with boys more frequently exposed than girls to such experiences as physical assault with or without a weapon and theft. The sex differences found in this sample were similar to those in previous research, with boys often experiencing more physical assaults than girls (Turner et al., 2010).

Significant co-occurrences were found among the seven victimization forms, with most children (84.5\%) experiencing more than two victimization forms during their lifetime. In particular, in this schoolaged sample, exposure to peer and/or sibling victimization and conventional crimes were most prominently reported. In addition, while considerable overlap was found among all victimization forms, the overlap was most prominent in more severe victimization forms (i.e., sexual and Internet victimization, maltreatment, and exposure to family violence).

Despite methodological differences, frequency rates of lifetime victimization in the current study were comparable to those found in past studies (e.g., Finkelhor, Ormrod, et al., 2009; Finkelhor, Turner, et al., 2009; Gustafsson, Nilsson, \& Svedin, 2009; Mrug, Loosier, \& Windle, 2008). Indeed, the obtained range of victimization experiences (0-23) and mean (5.5), which excluded the supplementary scales (Internet victimization and exposure to family violence), was similar to the range and mean obtained by a nationally representative U.S. study of 1,467 children aged two to 17 (i.e., 0-26, mean 3.6; Finkelhor, Turner, et al., 2009). More specifically, Finkelhor, Ormrod, and Turner (2009) presented rates of lifetime victimization by age (see Table 4 ).

Table 4

Percentage of Sample with Lifetime Victimization Compared to NATSCEV Rates

\begin{tabular}{lcc}
\hline & Current sample rates (6-12 yrs) & NATSCEV sample rates (6-13 yrs) \\
\hline Any sexual victimization & 9.4 & 7.2 \\
Any physical assaults & $\mathbf{8 2 . 6}$ & 62.4 \\
Any maltreatment & $\mathbf{2 7 . 7}$ & 18.9 \\
Any property victimization & 39.9 & 41.5 \\
Any witness victimization & 31.9 & 36.2 \\
Any indirect victimization $^{\text {a }}$ & 12.7 & 19.4 \\
\hline
\end{tabular}

Note.

${ }^{a}$ This scale excludes household theft and school bomb or attack threat to make it comparable to Finkelhor, Ormrod, Turner, and Holt (2009). As Finkelhor and these colleagues (2009) separated victimization rates by $6-9$ yrs and $10-13$ yrs $(\mathrm{N}=1824)$, the following equation was used to calculate the mean percentage based on unequal sample size: $\left(\mathrm{K}_{\mathrm{a}}+\mathrm{K}_{\mathrm{b}}\right) / \mathrm{N}_{\text {oftotalsample }}$ where $\mathrm{K}$ is the number of participants with the victimization. Statistical significance of the differences among rates of victimization was calculated by way of a series of two-sample difference of proportion tests. In addition, bolded frequencies are significant at a .01 level. 
Our findings were generally similar to results from the National Survey of Children's Exposure to Violence (NATSCEV). While the current sample was found to experience significantly more lifetime physical assaults and maltreatment, it is unclear whether these differences are a result of methodological or demographic differences among the samples. The inclusion of 13-year-olds in the NATSCEV may have confounded frequencies depending on victimization types. For example, Finkelhor, Ormrod, and Turner (2009) found that rates of property victimization (i.e., theft) and physical assault (i.e., assault without a weapon, bullying) peaked in midchildhood (six to nine years of age), and therefore the inclusion of 13-yearolds in the NATSCEV may have lowered the sample average. Higher rates of lifetime maltreatment in our study may have been a function of the anonymous study design. Unlike the NATSCEV study that utilizes telephone-survey design (where researchers were bound to report child abuse or neglect), caregivers in our study could not be identified; so they may have been more willing to accurately report maltreatment experiences. More generally, differences among community violence rates in the United States compared to the Ottawa (Canada) area may explain these obtained differences.

\section{Limitations}

It is important to note several limitations in the study's methodology. First, the current study was crosssectional in nature and, as such, the precise nature of relationships among variables cannot be determined. Furthermore, the current study relied on a convenience sample and, as such, the generalizability of findings to the Canadian population is unknown. However, a comparison of our sample to Statistics Canada data speaks to the similarities in socio-demographic variables between study participants and Ottawa/Gatineau population. The accuracy of lifetime recall also cannot be guaranteed. Indeed, selective recall may artificially enhance the association between psychological difficulties and victimization experiences (Widom, Raphael, $\&$ DuMont, 2004). That is, caregivers that have children who are presenting significant psychological difficulties may be more apt to remember their children's victimization experiences in order to help elucidate their children's difficulties. As such, it is possible that the association between multiple victimization and psychological difficulties was inflated.

The use of proxy reports raises important questions surrounding validity, especially for such constructs as victimization. The use of the self-reported JVQ, however, is not recommended for children under the age of nine years, as researchers suggest young children may have difficulty understanding the items, may be less honest in their responses, and may lack the memory retrieval skills required to report on a narrow time frame (Finkelhor, Hamby, et al., 2005). In a similar vein, in a study on the victimization experiences of welfare children, Cyr and colleagues (2012) used the caregiver version of the JVQ as two focus groups found that youth under the age of 12 had difficulty understanding the implications of informed consent. The JVQ-CR and the JVQ self-report (JVQ-SR) have been compared to assess respondent effects, and no evidence of reporter bias has been found (Finkelhor, Hamby, et al., 2005; Finkelhor, 2009). Notably, a recent U.S. nationally representative study (NATSCEV) compared response patterns of nine- (i.e., caregiver reports) and 10-yearolds (i.e., self-reports) on the JVQ-R1 and found no differences among caregiver reports and self-reports on maltreatment and caregiver-perpetrated victimization (Finkelhor, Turner, et al., 2009). It was anticipated that this autonomous Internet design would enable researchers to gather more accurate victimization data 
by perhaps discouraging some caregivers from misrepresenting children's victimization experiences out of fear of reprisal (e.g., child welfare involvement). Indeed, research has demonstrated that participants in Internet-administrated studies tend to engage in less socially desirable responding than participants in either traditional paper-and-pencil or phone interview administrations (Gosling, Vazire, Srivastava, \& John, 2004).

In a similar vein, as this study relied upon single informants (i.e., caregivers), common method variance may have contributed to an overestimation of the association among variables. There exist additional limitations related to the dichotomous measurement of victimization experiences. A continuous measurement of victimization, as well as an evaluation of the severity of the victimization (e.g., use of weapons, injury), would have strengthened and nuanced the construct of victimization. It can be argued that the dichotomous strategy employed in the current study limited the sensitivity of the victimization construct, thereby reducing our ability to detect relationships. Future research should endeavor to address the above-mentioned methodological and conceptual limitations.

\section{Conclusion}

The prevalent interconnections among victimization forms indicate that both researchers and clinicians need to inquire about a broad range of potential victimizations in both research and applied settings in order to obtain a comprehensive portrait of children's experiences and the way these experiences might influence psychosocial functioning. Indeed, consideration and assessment of the co-occurring forms of victimization are critical in the identification and treatment of children who have been exposed to any form of victimization, and such findings indicate that intervention and assessment efforts need to pay particular attention to, and be aware of the fact that children exposed to one form of victimization are likely to have experienced other forms of victimization as well. The ubiquitous nature of the co-occurrences among victimization forms suggests that targeting one form of victimization may have an impact on other victimization forms (e.g., reduction in one may lead to reduction in another) (Hamby \& Grych, 2013). Attempts to unravel and better understand the co-occurrences among victimization forms will allow us to develop more holistic and complete theories of victimization and will aid in the development of preventive programs for at-risk children (Finkelhor, 2009). Hamby and Grych (2013) argue that this holistic approach to victimization in both research and applied settings, which requires integration and collaboration across disciplines, is the "second wave" of victimization/violence scholarship. Additional developmentally specific and theoretically driven studies that examine the full scope of victimization to which children are exposed and that aim to disentangle the interconnections among victimization forms, their common and unique risk factors, as well as their sequelae, are needed to fortify our foundation of knowledge on childhood victimization. Such scientific inquiry is essential for effective prevention and treatment.

\section{NOTE}

1. Poly-victimized children were classified using the following classification: six years $>9$ victimization types; 7-10 years $>10$ types; $11-12$ years $>12$ types. No weighting techniques were used to classify poly-victimization based on preliminary analyses which indicated no statistically significant effects of weighting on the prediction of psychosocial functioning. 


\section{REFERENCES}

Boney-McCoy, S., \& Finkelhor, D. (1996). Is youth victimization related to trauma symptoms and depression after controlling for prior symptoms and family relationship? A longitudinal prospective study. Journal of Consulting and Clinical Psychology, 64, 1406-1416. doi: 0022-006X/96

Briere, J. (2005). Trauma Symptom Checklist for Young Children (TSCYC). Odessa, FL: Psychological Assessment Resources.

Briere, J., Johnson, K., Bissada, A., Damon, L., Crouch, J., Gil, E., Hanson, R., \& Ernst, V. (2001). The Trauma Symptom Checklist for Young Children (TSCYC): Reliability and association with abuse exposure in a multi-site study. Child Abuse \& Neglect, 25, 1001-1014. doi: 10.1016/S0145-2134(01)

Cicchetti, D., \& Lynch, M. (1993). Toward an ecological/transactional model of community violence and child maltreatment: Consequences for children's development. Psychiatry, 56, 96-118. Retrieved from http://search.proquest. com/docview/61368433?accountid $=14701$

Cyr, K., Chamberland, C., Clément, M.-È., Lessard, G., Wemmers, J., Collin-Vezina, D., Gagner, M.-H., \& Damant, D. (2013). Polyvictimization and victimization of children and youth: Results from a populational survey. Child Abuse \& Neglect, 37, 814-20. doi: 10.1016/j.chiabu.2013.03.009

Cyr, K., Chamberland, C., Lessard, G., Clément, M.-È., Wemmers, J., Collin-Vezina, D., Gagner, M.-H., \& Damant, D. (2012). Polyvictimization in a child welfare sample of children and youths. Psychology of Violence, 2, 385-400. doi: $10.1037 / \mathrm{a} 0028040$

Cyr, K., Clément, M.-È., \& Chamberland, C. (2013). Lifetime prevalence of multiple victimizations and its impact on children's mental health. Journal of Interpersonal Violence, 29, 616-634. doi:10.1177/0886260513505220

Finkelhor, D. (2009). Childhood victimization: Violence, crime and abuse in the lives of young people. New York: Oxford University Press.

Finkelhor, D., \& Dziuba-Leatherman, J. (1995).Victimization prevention programs: A national survey of children's exposure and reactions. Child Abuse \& Neglect, 19, 129-139. doi: 10.10170S0954579407070083

Finkelhor, D., Hamby, S., Ormrod, R., \& Turner, H. A. (2005). The juvenile victimization questionnaire: Reliability, validity, and national norms. Child Abuse \& Neglect, 29, 383-412. doi:10.1016/j.chiabu.2004.11.001

Finkelhor, D. \& Hashima, P. (2001). The victimization of children \& youth: A comprehensive overview. In S. O. White (Ed.), Law and Social Science Perspectives on Youth and Justice. (pp. 49-78). New York: Plenum.

Finkelhor, D., Ormrod, R. K., \& Turner, H. A. (2007a). Polyvictimization and trauma in a national longitudinal cohort. Development and Psychopathology, 19, 149-166.

Finkelhor, D., Ormrod, R. K., \& Turner, H. A. (2007b). Re-victimization patterns in a national longitudinal sample of children and youth. Child Abuse \& Neglect, 31, 479-502. doi:10.1016/j.chiabu.2006.03.012

Finkelhor, D., Ormrod, R. K., \& Turner, H. A. (2007c). Poly-victimization: A neglected component in child victimization. Child Abuse \& Neglect, 31, 7-26. doi:10.1016/j.chiabu.2006.06.008

Finkelhor, D., Ormrod, R. K., \& Turner, H. A. (2009). Lifetime assessment of poly-victimization in a national sample of children and youth. Child Abuse \& Neglect, 33, 403-11. doi: 10.1016/j.chiabu.2008.09.012

Finkelhor, D., Ormrod, R. K., Turner, H. A., \& Hamby, S. L. (2005). The victimization of children and youth: A comprehensive, national survey. Child Maltreatment, 10, 5-25. doi: 10.1177/1077559504271287

Finkelhor, D., Ormrod, R. K., Turner, H. A., \& Holt, M. (2009). Pathways to poly-victimization. Child Maltreatment, 14, 316-29. doi: 10.1177/1077559509347012

Finkelhor, D., Turner, H. A., Hamby, S. L., \& Ormrod, R. K. (2011). Polyvictimization: Children's exposure to multiple types of violence, crimes and abuse. Office of Justice Program: Juvenile Justice Bulletin, no. 235504, 1-12.

Finkelhor, D., Turner, H. A., Ormrod, R., \& Hamby, S. (2009). Violence, abuse and crime exposure in a national sample of children and youth. Pediatrics, 124, 1411-1422. doi: 10.1542/peds.2009-0467

Gannon, M., \& Mihorean, K. (2005). Criminal victimization in Canada, 2004. Catalogue no. 85-002. Ottawa: Statistics Canada.

Gosling, S. D., Vazire, S., Srivastava, S., \& John, O. P. (2004). Should we trust Web-based studies? A comparative analysis of six preconceptions about Internet questionnaires. American Psychologist, 59, 93-104. doi: 10.1037/0003-066X.59.2.93 
Grych, J. H., \& Swan, S. C. (2012). Toward a more comprehensive understanding of interpersonal violence: Introduction to the special issue on interconnections among different types of violence. Psychology of Violence, 2, $105-110$. doi: $10.1037 / \mathrm{a} 0027616$

Gustafsson, P. E., Nilsson, D., \& Svedin, C. G. (2009). Polytraumatization and psychological symptoms in children and adolescents. European Child \& Adolescent Psychiatry, 18, 274-283. doi: 10.1007/s00787-008-0728-2

Hamby, S. L., Finkelhor, D., Ormrod, R., \& Turner, H. (2005). The Juvenile Victimization Questionnaire (JVQ): Administration and scoring manual. Durham, NH: Crimes Against Children Research Center. Retrieved from: http://www.unh.edu/ccrc/pdf/jvq/CV55newedition04.pdf

Hamby, S., \& Grych, J. M. (2013). The web of violence: Exploring connections among different forms of interpersonal violence and abuse. New York: Springer.

Holt, M. K., Finkelhor, D., \& Kantor, G. K. (2007). Multiple victimization experiences of urban elementary school students: Associations with psychosocial functioning and academic performance. Child Abuse \& Neglect, 31, 503-515. doi:10.1016/j.chiabu.2006.12.006

Hooven, C., Nurius, P. S., Logan-Greene, P., \& Thompson, E. A. (2012). Childhood violence exposure: Cumulative and specific effects on adult mental health. Journal of Family Violence, 27, 511-522. doi: 10.1007/s10896-012-9438-0

Mrug, S., Loosier, P. S., \& Windle, M. (2008). Violence exposure across multiple contexts: Individual and joint effects on adjustment. American Journal of Orthopsychiatry, 78, 70-84. doi: 10.1037/0002-9432.78.1.70

Nishina, A., \& Juvonen, J. (2005). Daily reports of witnessing and experiencing peer harassment in middle school. Child Development, 76, 435-450. doi: 10.1111/j.1467-8624.2005.00855.x

Romano, E., Babchishin, L. K., Marquis, R., \& Fréchette, S. (2014, in press). Childhood maltreatment and educational outcomes. Trauma, Violence \& Abuse.

Saunders, B. E. (2003). Understanding children exposed to violence: Toward an integration of overlapping fields. Journal of Interpersonal Violence, 18, 356-376. doi: 10.1177/0886260502250840

Statistics Canada. (2012a). Income and earning highlights. Statistics Canada catalogue no. 97-563-XWE2006002. Retrieved from: http://www.livingin-canada.com/compare-canadian-cities.html

Statistics Canada. (2012b). Faits saillants en tableaux Familles et ménages, Recensement de 2011. Statistique Canada catalogue no. 98-312-XWF2011002. Retrieved from: http://www12.statcan.gc.ca/census-recensement/2011/dp$\mathrm{pd} /$ hlt-fst/fam/index-fra.cfm?Lang=F

Statistics Canada. (2013). 2011 National Household Survey highlights: Factsheet 2. Office of Economic Policy: Labour and Demographics Analysis Branch. Retrieved from:http://www.fin.gov.on.ca/en/economy/demographics/census/ nhshi11-2.pdf

Stevens, T., Ruggerio, K., Kilpatrick, D., Resnick, H., \& Saunders, B. (2005). Variables differentiating singly and multiply victimized youth: Results from the National Survey of Adolescents and implications for secondary prevention. Child Maltreatment, 10, 211-223. doi: 10.1177/1077559505274675

Turner, H. A., Finkelhor, D., \& Ormrod, R. (2010). Poly-Victimization in a national sample of children and youth. American Journal of Preventive Medicine, 38, 323-330. doi: 10.1016/j.amepre.2009.11.012

Turner, H. A., Finkelhor, D., Ormrod, R., Hamby, S., Leeb, R. T., Mercy, J. A., \& Holt, M. (2012). Family context, victimization and child trauma symptoms: Variations in safe, stable and nurturing relationships during early and middle childhood. American Journal of Orthopsychiatry, 82, 209-219. doi: 10.1111/j.1939-0025.2012.01147.x

Widom, C. S., Raphael, K. G., \& DuMont, K. A. (2004). The case for prospective longitudinal studies in child maltreatment research: Commentary on Dube, Williamson, Thompson, Felitti, and Anda (2004). Child Abuse \& Neglect, 28, 715-722. doi: 10.1016/j.chiabu.2004.03.009 